\title{
Thoracic Nodule
}

National Cancer Institute

\section{Source}

National Cancer Institute. Thoracic Nodule. NCI Thesaurus. Code C157236.

A nodular lesion that develops in the chest wall. 